\title{
Neural Coding of Interaural Time Differences with Bilateral Cochlear Implants: Effects of Congenital Deafness
}

\author{
Kenneth E. Hancock, ${ }^{1,3}$ Victor Noel, ${ }^{2}$ David K. Ryugo, ${ }^{4}$ and Bertrand Delgutte ${ }^{1,3,5}$ \\ ${ }^{1}$ Eaton-Peabody Laboratory and ${ }^{2}$ Cochlear Implant Research Laboratory, Massachusetts Eye and Ear Infirmary, Boston, Massachusetts 02114, ${ }^{3}$ Department \\ of Otology and Laryngology, Harvard Medical School, Boston, Massachusetts 02115, ${ }^{4}$ Departments of Otolaryngology-Head and Neck Surgery and \\ Neuroscience, Johns Hopkins University School of Medicine, Baltimore, Maryland 21205, and ${ }^{5}$ Research Laboratory of Electronics, Massachusetts Institute \\ of Technology, Cambridge, Massachusetts 02139
}

Human bilateral cochlear implant users do poorly on tasks involving interaural time differences (ITD), a cue that provides important benefits to the normal hearing, especially in challenging acoustic environments, yet the precision of neural ITD coding in acutely deafened, bilaterally implanted cats is essentially normal (Smith and Delgutte, 2007a). One explanation for this discrepancy is that the extended periods of binaural deprivation typically experienced by cochlear implant users degrades neural ITD sensitivity, by either impeding normal maturation of the neural circuitry or altering it later in life. To test this hypothesis, we recorded from single units in inferior colliculus of two groups of bilaterally implanted, anesthetized cats that contrast maximally in binaural experience: acutely deafened cats, which had normal binaural hearing until experimentation, and congenitally deaf white cats, which received no auditory inputs until the experiment. Rate responses of only half as many neurons showed significant ITD sensitivity to low-rate pulse trains in congenitally deaf cats compared with acutely deafened cats. For neurons that were ITD sensitive, ITD tuning was broader and best ITDs were more variable in congenitally deaf cats, leading to poorer ITD coding within the naturally occurring range. A signal detection model constrained by the observed physiology supports the idea that the degraded neural ITD coding resulting from deprivation of binaural experience contributes to poor ITD discrimination by human implantees.

\section{Introduction}

Increasing numbers of profoundly deaf patients are receiving cochlear implants (CIs) in both ears with the goal of restoring the benefits of binaural hearing, including accurate sound localization and improved speech reception in noise. Although some benefits are observed in bilateral CI users, they differ from those experienced by normal-hearing listeners in that interaural time differences (ITDs) provide little advantage. Sound localization with bilateral CI is based primarily on interaural level differences (ILD) (van Hoesel, 2004; Seeber and Fastl, 2008), whereas improvements in speech reception in noise result from attending to the ear with the best signal-to-noise ratio (Litovsky et al., 2006). Bilateral CI provide little binaural "unmasking," which requires neural processing of ITD, and is important for understanding speech when multiple sound sources are widely distributed in space (Zurek, 1992).

Performance of bilateral CI users on basic psychophysical tasks is consistent with their sound localization and speech reception abilities. ILD discrimination is exquisitely fine $(\sim 0.2 \mathrm{~dB})$ using direct electric stimulation and comparable with normal hearing $(1-2 \mathrm{~dB})$ when listening through clinical processors (van

Received June 21, 2010; revised Aug. 10, 2010; accepted Aug. 12, 2010.

This work was supported by National Institutes of Health Grants R01 DC00575, R01 DC00232, and P30 DC005209, and a grant from the Advanced Bionics Corporation. We are grateful to Connie Miller for surgical support and Melissa Wood for histological processing.

Correspondence should be addressed to Kenneth E. Hancock, Eaton-Peabody Laboratory, Massachusetts Eye and Ear Infirmary, Boston, MA 02114. E-mail: Ken_Hancock@meei.harvard.edu.

DOI:10.1523/JNEUROSCI.3213-10.2010

Copyright $\odot 2010$ the authors $\quad 0270-6474 / 10 / 3014068-12 \$ 15.00 / 0$
Hoesel and Tyler, 2003; Laback et al., 2004; Grantham et al., 2008). Conversely, ITD sensitivity is typically poorer than normal and restricted to a narrow range of stimulus conditions. For the best performers, just noticeable differences (JNDs) in ITD are on the order of $50 \mu$ s for low-rate pulse trains, comparable with JNDs in normal-hearing listeners for similar stimuli (Laback et al., 2007). However, ITD JNDs with bilateral CIs are highly variable across subjects, reaching several hundreds of milliseconds in some listeners, and degrade rapidly for pulse rates above 300 pulses per second (pps) (Lawson et al., 1998; van Hoesel and Tyler, 2003; Laback et al., 2007; van Hoesel, 2007; Poon et al., 2009).

In contrast to the typically poor ITD discrimination exhibited by human CI listeners, coding of ITD by inferior colliculus (IC) neurons is essentially as precise in acutely deafened, bilaterally implanted cats as in normal-hearing cats (Smith and Delgutte, 2007a). An important difference between human psychophysics and animal neurophysiology is the extent of deprivation of binaural experience. The acutely deafened cats studied by Smith and Delgutte (2007a) had normal binaural hearing until experimentation, whereas human CI wearers typically experience long periods of auditory deprivation before receiving their first implant and, in many cases, an additional period of binaural deprivation before the second implantation. Such extended periods of deprivation, especially if they include the neonatal period, may degrade neural ITD sensitivity by inducing changes in brainstem neural circuits involved in ITD processing or preventing these circuits from developing normally. 
As an initial test of this hypothesis, we recorded from single units in the IC of two groups of bilaterally implanted cats representing the maximum contrast in auditory experience: acutely deafened cats, who had normal hearing before the experiment, and congenitally deaf white cats, who had no auditory experience. We found approximately half as many ITD-sensitive neurons in the congenitally deaf animals compared with the acutely deafened animals and abnormalities in ITD tuning among the neurons that were ITD sensitive. Using a computational model, we show that these physiological differences are likely to have a major impact on psychophysical ITD discrimination.

\section{Materials and Methods}

Experiments were performed on 11 barbiturate-anesthetized cats of either sex, divided into two groups. Seven were congenitally deaf white cats raised at Johns Hopkins University. In these animals, the organ of Corti degenerates before the onset of hearing (West and Harrison, 1973; Heid et al., 1998), so that they presumably never hear. The other four were adult cats acutely deafened by coadministration of kanamycin $(300 \mathrm{mg} /$ $\mathrm{kg}$, s.c.) and ethacrynic acid ( $25 \mathrm{mg} / \mathrm{kg}$, i.v.) 1 week before implantation and experimentation (Xu et al., 1993). The congenitally deaf cats may represent a model for early onset (prelingual) deafness in terms of binaural experience, whereas the acutely deafened cats model sudden-onset deafness occurring in adulthood. All procedures were approved by the animal care committees at the Massachusetts Eye and Ear Infirmary, the Massachusetts Institute of Technology, and Johns Hopkins University.

There is considerable variability among white cats in the degree and type of cochlear pathology (Ryugo et al., 1998, 2003). To ensure that the white cats used in the present experiments were profoundly deaf, auditory brainstem responses (ABRs) to either clicks or tone pips were measured at 4 and 8 postnatal weeks in the laboratory of D.K.R. (Ryugo et al., 2003). Only animals that showed no response in either ear at the highest level tested $[\sim 100 \mathrm{~dB}$ sound pressure level (SPL)] were used in the present experiments.

\section{Surgery and cochlear implantation}

Surgical and experimental procedures were performed under barbiturate anesthesia, either single injections of Dial in urethane $(75 \mathrm{mg} / \mathrm{kg}$, i.p.) or separate injections of Nembutal (37 mg/kg, i.p.) and urethane $(300 \mathrm{mg} /$ $\mathrm{kg}$, i.p.). Supplemental doses were administered as needed to maintain areflexia to a toe pinch. Dexamethasone $(\sim 0.2 \mathrm{ml}$, i.m. $)$ was given every $4 \mathrm{~h}$ to minimize brain swelling. The trachea was cannulated, and body temperature was maintained at $37^{\circ} \mathrm{C}$ by means of a feedback-controlled heating blanket. Heart rate, respiration rate, and expired $\mathrm{CO}_{2}$ were monitored continuously throughout the experiment.

The posterior and dorsal aspects of the skull were exposed, and the ear canals were cut to allow insertion of closed acoustic systems. The tympanic bullae were opened to expose the round window, and then cats were implanted bilaterally with eight-contact intracochlear animal electrode arrays (Cochlear Corp.) through a small cochleostomy near the round window. Electrode arrays were inserted 5-6 $\mathrm{mm}$ and secured in place using dental cement. A craniotomy was performed over the occipital cortex, which was aspirated to gain access to the IC. A portion of the bony tentorium was removed to maximize the exposure.

\section{Stimulus generation}

Electrical stimuli were generated by a 16-bit digital-to-analog converter (National Instruments model PXI-6221) and delivered to the intracochlear arrays through custom, high-bandwidth current sources. Stimuli were presented in a wide bipolar electrode configuration, between the most apical and most basal electrode in the array ( $5.25 \mathrm{~mm}$ separation). This configuration is similar to the monopolar configuration used in clinical devices in that it stimulates neurons throughout the tonotopic axis, but the stimulus artifact is reduced compared with a monopolar configuration (Litvak et al., 2003). Like monopolar stimulation, the wide bipolar configuration produces spatial excitation patterns with a single maximum across the tonotopic axis of the IC (Smith and Delgutte, 2007a).

\section{ABRs}

ABRs were measured with both acoustic stimulation, to verify deafness, and electrical stimulation, to assess overall neural sensitivity. ABRs were measured between a bone screw inserted in the vertex of the skull and the stereotaxis apparatus (David Kopf Instruments model 1404). Signals were amplified (acoustic, $94 \mathrm{~dB}$ gain; electric, $66 \mathrm{~dB}$ ), filtered (0.1-10 $\mathrm{kHz}$ ) and sampled at $25 \mathrm{kHz}$ using a 16-bit analog-to-digital converter (National Instruments model PXI-6221). Responses to 500 stimulus presentations were averaged. Electric stimuli were biphasic current pulses (50 $\mu \mathrm{s} /$ phase) presented at $21 / \mathrm{s}$ in wide bipolar configuration and alternated in polarity to cancel stimulus artifact. Acoustic stimuli were $50 \mu \mathrm{s}$ condensation clicks presented at 21/s through a Realistic 40-1377 tweeter enclosed in a calibrated acoustic assembly inserted into the ear canal. No acoustically evoked responses were observed up to the highest levels tested ( $\sim 100 \mathrm{~dB}$ SPL peak).

The binaural interaction component (BIC) of the electric ABR was measured. First, the relative level between the ears was adjusted to produce equal amplitude wave 4 responses to monolateral stimulation (Smith and Delgutte, 2007b). Wave 4 in cat corresponds to wave V in human ABRs and is generated by lemniscal inputs to the IC (Melcher and Kiang, 1996). After level adjustment, the sum of the responses to stimulation of each ear alone was subtracted from the response to bilateral stimulation to obtain the ABR. The BIC is typically a biphasic waveform (see Fig. 1), and its amplitude was measured between its trough and the following peak (arrows).

\section{Single-unit recordings}

Silicon substrate microelectrode arrays with 16 contacts $\left(177 \mu \mathrm{m}^{2}\right.$ contact area, 100 or $150 \mu \mathrm{m}$ spacing between contacts; NeuroNexus) were used for single-unit recordings from the IC. The electrode array was gradually advanced vertically into the IC from dorsal to ventral with a microdrive until the tip reached a maximum depth of $\sim 5 \mathrm{~mm}$. In every animal, we sampled the central regions of the IC in which neurons are known to be ITD sensitive in response to electric stimulation (Smith and Delgutte, 2007b). When time permitted, more anterior and posterior regions were sampled as well. Every single unit that could be isolated was characterized, whether it was ITD sensitive or not.

Signals from the microelectrode were amplified and bandpass filtered (300-3000 Hz; RA16; Tucker-Davis Technologies). Typically, signals from adjacent contacts were subtracted to minimize the amplitudes of stimulus artifacts and local field potentials. Subtracted signals were sampled at $200 \mathrm{kHz}$ (National Instruments model PXI-6123), and custom software was used to blank residual stimulus artifacts and detect the times of action potentials by threshold crossing. Only well isolated single units were studied.

Biphasic electric pulses (anodic/cathodic, $50 \mu \mathrm{s} /$ phase) alternately delivered to the left ear, the right ear, and both ears simultaneously at a rate of $10 / \mathrm{s}$ were used as search stimuli. Once a single unit was isolated, its response to the search stimulus was measured as a function of stimulus level in 1 or $2 \mathrm{~dB}$ increments to determine the threshold for stimulation of each ear. ITD sensitivity was then studied with pulse train stimuli.

Characterization of ITD sensitivity. Stimuli were low-rate (10-80 pps) periodic trains of biphasic current pulses (anodic/cathodic, $50 \mu \mathrm{s} / \mathrm{phase}$ ). Neural responses were measured as a function of ITD at stimulus levels 1-6 dB re single-pulse threshold. ITD was varied either statically or dynamically. Static-ITD pulse trains were $300 \mathrm{~ms}$ in duration, with a 300 ms silent interval between presentations. The ITD of each pulse was constant within a train but varied across presentations, typically from $-2000 \mu$ s (ipsilateral-leading) to $+2000 \mu$ s (contralateral-leading) in $200 \mu$ s steps. Each ITD was typically presented 10-20 times in random order. Dynamic-ITD stimuli (Smith and Delgutte, 2007a) were continuous pulse trains with a rate of 40 pps. Every pulse was presented at a different ITD to create a "binaural pulse beat" stimulus. Specifically, ITD increased from -2000 to $+2000 \mu$ s in $200 \mu$ s steps over $0.5 \mathrm{~s}$ and then decreased back to $-2000 \mu \mathrm{s}$ in $0.5 \mathrm{~s}$; the whole $1 \mathrm{~s}$ cycle was typically repeated 20 times with no silent interval.

\section{Data analysis}

Temporal discharge patterns. Temporal response patterns to pulse stimuli were characterized using period histograms computed from responses to 
Table 1. Human subject characteristics

\begin{tabular}{|c|c|c|c|c|c|c|c|c|}
\hline \multirow[b]{2}{*}{ Subject } & \multirow[b]{2}{*}{ Sex } & \multirow[b]{2}{*}{ Etiology } & \multicolumn{2}{|c|}{$\begin{array}{l}\text { Age at profound loss } \\
\text { (years) }\end{array}$} & \multicolumn{2}{|c|}{$\begin{array}{l}\text { Age at onset of } \mathrm{Cl} \text { use } \\
\text { (years) }\end{array}$} & \multirow{2}{*}{$\begin{array}{l}\text { Duration of bilateral } \\
\text { deprivation (years) }\end{array}$} & \multirow{2}{*}{$\begin{array}{l}\text { Duration of bilatera } \\
\text { Cl use (years) }\end{array}$} \\
\hline & & & Right & Left & Right & Left & & \\
\hline C109 & Female & Genetic & 44 & 44 & 48 & 50 & 6 & 5 \\
\hline C128 & Male & Genetic & 25 & 25 & 36 & 39 & 14 & 2.5 \\
\hline
\end{tabular}

static-ITD stimuli. For each ITD, spike times relative to the onset of the preceding stimulus pulse were binned with $0.5 \mathrm{~ms}$ resolution. The first pulse cycle in each $300 \mathrm{~ms}$ train was excluded from the analysis. Period histograms for a range of ITDs were added together to obtain enough spikes for quantification of the temporal discharge pattern. Period histograms were only pooled across ITDs for which the first spike latency was less than the median plus a small tolerance $(2.5 \%)$. This selection procedure ensures that pooling does not smear the temporal discharge pattern. It is effective because we vary ITD by systematically delaying the stimulus in the lagging ear, keeping the leading-ear delay constant.

Period histograms exhibited a precisely timed early response (less than $\sim 25 \mathrm{~ms}$ latency), a poorly timed late response (more than $\sim 25 \mathrm{~ms}$ ), or both. These components were quantified by fitting each period histogram with a sum of two Gaussian functions with different latencies. The mean latencies were constrained to nonoverlapping intervals $(<25 \mathrm{~ms}$ and $>25 \mathrm{~ms}$ ) to capture the early and late responses, respectively. A response component (i.e., early or late) was judged to be present if the area under the corresponding Gaussian contained at least 20 spikes. The mean and SD of the Gaussian fit to the early response were used to quantify the latency and jitter, respectively, of pulse-evoked spikes.

Quantification of ITD sensitivity. ITD sensitivity of single-unit rate responses was quantified using a signal-to-noise ratio (SNR) metric based on ANOVA. For static-ITD stimuli, the spike count was summed over the entire $300 \mathrm{~ms}$ stimulus duration for each repetition. For dynamic-ITD stimuli, spike counts for each ITD were summed for the ascending and descending part of each $1 \mathrm{~s}$ ITD cycle. In either case, the ITD SNR was defined as follows:

\section{ITD SNR}

$$
=\frac{\text { Variance in spike count attributable to variation in ITD }}{\text { Total variance in firing rates }} \text {. }
$$

ITD SNR is the fraction of the variance in neural spike counts accounted for by the variation in stimulus ITD, as opposed to random variability across stimulus trials. It ranges from 0 , indicating no ITD sensitivity, to 1 , indicating perfectly reliable ITD coding (meaning that the spike counts for each ITD would be identical on every trial). Details of the ITD SNR computation are provided in the supplemental data (available at www. jneurosci.org as supplemental material).

An $F$ test was used to determine whether the dependence of firing rate on ITD was statistically significant $(p<0.025)$. Summary data are shown for the stimulus condition (stimulus level and pulse rate) that maximizes the ITD SNR. Most of these summary plots combine data obtained in response to static-ITD and dynamic-ITD stimuli because the two responses were generally similar in cases when both were available from the same neuron.

Quantification of ITD tuning. For neurons with significant ITD SNRs, rate-ITD curve shapes were categorized using the four templates of Smith and Delgutte (2007a): peak (positive-going Gaussian), trough (negative-going Gaussian), biphasic (difference of two Gaussians), or sigmoidal (cumulative Gaussian). The data were fit to each of the four templates using the MATLAB function lsqcurvefit (MathWorks). Each rate-ITD curve was assigned the category of the template that yielded the smallest sum-of-squared errors. The best fit was generally quite good (95\% of the fits had $r^{2}>0.5$, median of 0.88 ).

Figure $8 \mathrm{~A}$ illustrates metrics of ITD tuning computed from the best fits to peak-shaped rate-ITD curves and peak portions of biphasic curves. The best ITD is the ITD corresponding to the peak of the fitted curve. The half-width is the difference in ITD between the two points of the fitted curve having $50 \%$ of the peak amplitude. The ITD of maximum slope
$\left(\mathrm{ITD}_{\mathrm{MS}}\right)$ is the point on the fitted curve where the rate is most sensitive to changes in ITD.

\section{Neural population model of ITD discrimination}

To assess the functional implications of the deficits in neural ITD sensitivity observed in congenitally deaf cats, a computational model (Hancock and Delgutte, 2004) that predicts normal-hearing ITD discrimination based on physiological properties of IC neurons was extended to the bilateral CI case. Figure $10 \mathrm{~A}$ shows a block diagram of this detection theoretic model. The model for the CI case comprises a two-dimensional grid of model neurons, each of which has a Gaussian-shaped rate-ITD curve. The SD of the Gaussian (sharpness of ITD tuning) varies systematically along one axis of the grid (corresponding to the tonotopic axis in the normalhearing case), according to a lognormal distribution fit to the physiological data. The ITD of maximum slope varies along the other axis of the grid according to a normal distribution.

The model simulates a two-alternative forced-choice ITD discrimination experiment by comparing model neural firing rates in response to a reference ITD and a test ITD. Model rates are first summed along the columns of the grid (i.e., across neurons differing in sharpness of tuning). This summation was found to be essential for predicting the dependence of ITD JND on reference ITD in the model for normal hearing (Hancock and Delgutte, 2004). Then, for each column $i$, the summed rates $r_{i}$ are used to compute a standard separation $D_{i}$ (analogous to $d^{\prime}$ in psychophysics):

$$
D_{i}=\frac{r_{i}\left(\operatorname{ITD}_{\text {test }}\right)-r_{i}\left(\operatorname{ITD}_{\text {ref }}\right)}{\sqrt{\frac{1}{2}\left[\sigma_{i}^{2}\left(\operatorname{ITD}_{\text {test }}\right)+\sigma_{i}^{2}\left(\operatorname{ITD}_{\text {ref }}\right)\right]}} .
$$

The firing rate variance across trials, $\sigma^{2}$, is assumed to be proportional to the mean firing rate (Hancock and Delgutte, 2004). The individual standard separations are combined optimally (Green and Swets, 1988), assuming statistically independent firing rates across columns, to get the overall standard separation $D$ :

$$
D^{2}=\varepsilon \sum_{i} D_{i}^{2}
$$

The test ITD is adjusted to find the value yielding $D=0.77$ (equivalent to $71 \%$ correct). The difference between this test ITD and the reference ITD is taken as the predicted ITD JND. The model has only one free parameter, the "detection efficiency" $\varepsilon$ (Eq. 3), which is an overall scale factor on the JNDs predicted by the model. For all simulations, $\varepsilon$ was held constant at the value that produces accurate predictions of ITD discrimination performance for broadband noise in normal hearing (Hancock and Delgutte, 2004). Thus, the model for the CI case is completely constrained by the IC physiology in deaf animals on the one hand and the normal-hearing performance on the other hand and has no free parameter.

\section{Human psychophysics}

In normal-hearing listeners, the ITD JND is best for stimuli near the midline and degrades as the reference ITD is moved away from the midline (Mossop and Culling, 1998); whether this trend also applies with CI is unknown. To provide psychophysical data with which to test the neural population model for the CI case, ITD JNDs were measured as a function of reference ITD in two Advanced Bionics CII implant subjects, both with above-average discrimination performance. Table 1 summarizes the auditory experience of these subjects, including their age at the time of the experiment, the duration of deafness before receiving the first cochlear implant, the length of time between implantations, and the 

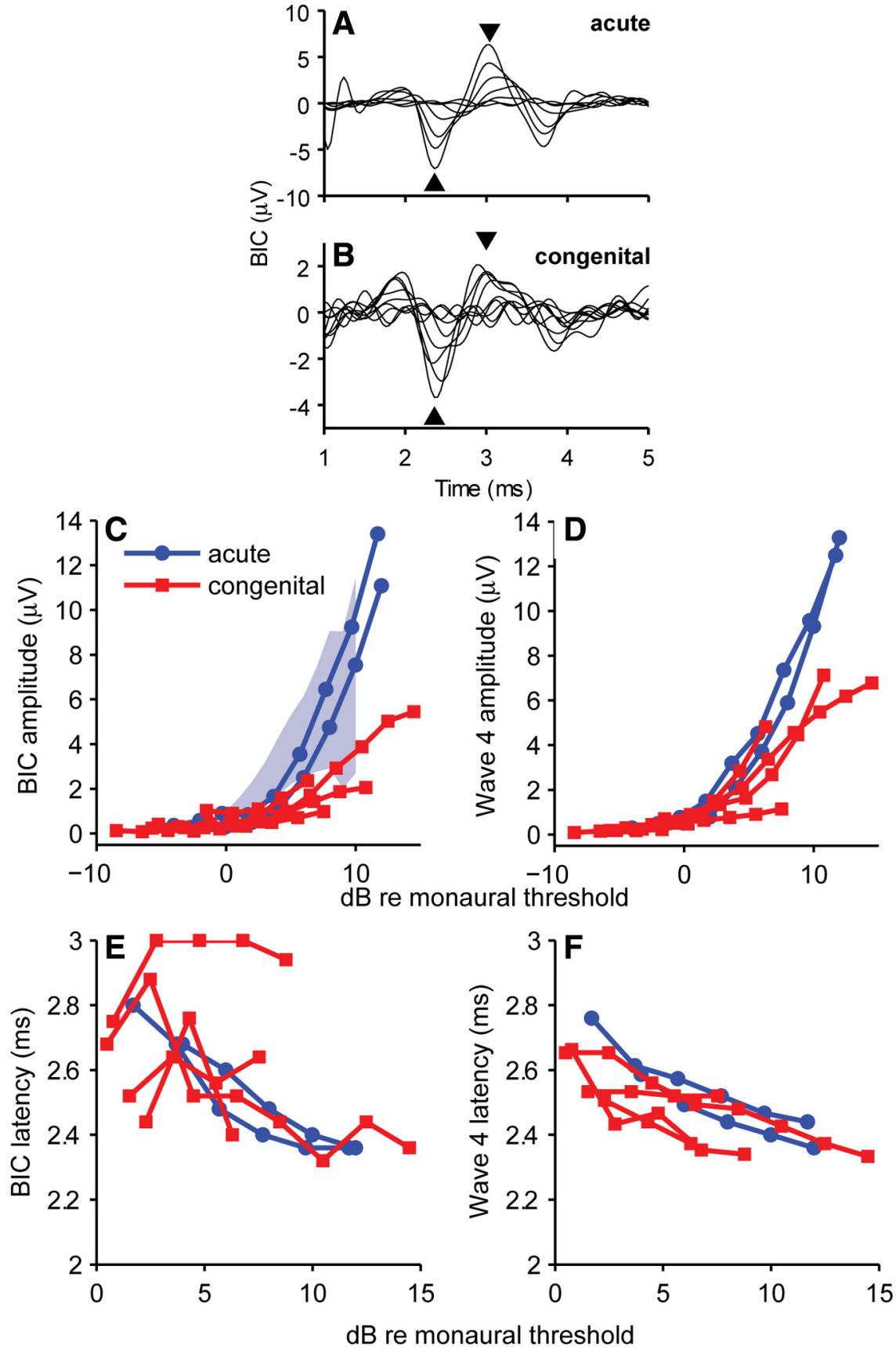

Figure 1. The BIC of ABR is reduced in congenitally deaf cats. $\boldsymbol{A}, \boldsymbol{B}$, Example BIC waveforms from one acutely deafened cat $(\boldsymbol{A})$ and one congenitally deaf cat $(\boldsymbol{B})$. Each trace corresponds to a different stimulus level. BIC amplitude was measured between the notch and the following peak (arrows). C, BIC amplitudes as a function of stimulus level in congenitally deaf and acutely deafened cats. Gray shading shows the range of BIC amplitudes measured in acutely deafened cats by Smith and Delgutte (2007b). D, Monaural wave 4 amplitudes are also smaller in congenitally deaf cats. Amplitudes shown are average of responses to stimulation of each ear alone. $E, B I C$ latencies are similar between congenitally deaf and acutely deafened cats, with the exception of one cat. $F$, Monaural wave 4 latencies tend to be shorter in congenitally deaf cats. Values shown are averages for stimulation of each ear alone. In $\boldsymbol{B}-\boldsymbol{F}$, stimulus levels are expressed relative to the monaural ABR thresholds, defined as the stimulus amplitude required to evoke $1 \mu \mathrm{V}$ wave 4 . Monaural wave 4 amplitudes were always equalized during binaural stimulation by application of an appropriate ILD.

duration of experience with bilateral implants. Custom interface hardware bypassed the wearable speech processors to control the implanted current stimulators directly. Human subject procedures were approved by the Internal Review Board of the Massachusetts Eye and Ear Infirmary.

The stimuli were periodic trains of biphasic pulses (cathodic/anodic, $27 \mu \mathrm{s} /$ phase) presented at a rate of $50 \mathrm{pps}$ to a single binaural electrode pair. Electrode pairs were selected to maximize binaural image fusion, interaural pitch matching, and ITD sensitivity (Poon et al., 2009). During each trial, the subject was presented with two $300 \mathrm{~ms}$ stimuli separated by a $300 \mathrm{~ms}$ silent interval. The ITD of the first stimulus was always the reference ITD, which remained fixed for an entire adaptive threshold run. The ITD of second stimulus was either incremented or decremented by an amount $\Delta \mathrm{ITD}$. The subject's task was to report whether the second stimulus was heard to the left or right of the first using a keyboard. Feedback was provided after every trial.

The ITD JND was measured using a twodown one-up adaptive procedure converging to $71 \%$ correct performance (Levitt, 1971). The threshold was initially calculated as the mean $\triangle$ ITD for the last 8 of 14 total reversals and then scaled by $\sqrt{ } 2$ to yield JNDs comparable with those that would be obtained using a standard two-interval, two-alternative forcedchoice paradigm (Hartmann and Rakerd, 1989). (Our procedure differed from the standard in that the first interval always contained the reference ITD.) ITD JNDs were measured at four reference ITDs: 0, 215, 646, and 1077 $\mu$ s. For each subject, two or four runs were averaged to obtain the final JND for each reference ITD (except for the $1077 \mu$ s reference, in which there was only one run).

\section{Results}

\section{ABR binaural interaction component}

The binaural interaction component of the ABR (Dobie and Norton, 1980; Levine, 1981) specifically reflects the activity of neural populations whose activity is modulated by binaural stimulation, including those responsible for processing and encoding ITD. Figure $1, A$ and $B$, shows BIC waveforms measured in response to biphasic electric pulses from one acutely deafened cat and one congenitally deaf cat, respectively. The two sets of waveforms are broadly similar, with a prominent negative deflection at $2.3 \mathrm{~ms}$ latency, followed by a positive deflection at $3 \mathrm{~ms}$. However, the peak BIC amplitude is larger for the acutely deafened cat than for the congenitally deaf cat (note the different vertical scales in Fig. $1 A, B$ ). Figure $1 C$ shows BIC amplitudes for all cats tested as a function of stimulus level relative to monaural threshold. BIC amplitudes from acutely deafened cats fall in the range measured by Smith and Delgutte (2007b) in the same preparation, whereas those from congenitally deaf cats are consistently smaller. A decrease is also observed in the amplitude of monaural ABR wave 4 (Fig. $1 D$ ), so it is possible that the reduced BIC amplitude reflects a general decrease in neural responsiveness rather than a specific deficit in binaural processing. However, a significant difference between acutely deafened and congenitally deaf cats persists even after normalizing BIC amplitudes by the average monaural wave 4 
amplitude at each level ( $t$ test, $p=0.017$ ). Thus, the ABR data suggest there is a specific deficit in binaural processing in addition to an overall decrease in ABR amplitude, which may reflect a combination of decreased synchrony in neural activity and partial loss of spiral ganglion neurons in the congenitally deaf cats (Heid et al., 1998).

Wave 4 latencies were slightly shorter in congenitally deaf cats than in acutely deafened cats (Fig. $1 F$ ). BIC latencies were generally similar between the two groups, with the exception of one congenitally deaf cat, in which the BIC was delayed by $\sim 0.6 \mathrm{~ms}$ with respect to wave 4 (Fig. $1 E$ ). This animal did not yield enough single units to determine whether their responses were unusual compared with those of other deaf white cats.

Overall, these results suggest that, although congenital deafness does not preclude binaural interactions in the auditory brainstem, deprivation of auditory experience does impair binaural circuitry to a greater extent than monaural responses. These findings are consistent with the report that the ABR BIC has an abnormal latency on the first day of bilateral implant use in congenitally deaf children (Gordon et al., 2007).

\section{ITD sensitivity of IC neurons}

Consistent with the BIC results, we found that ITD coding by IC neurons is degraded in congenitally deaf cats compared with acutely deafened cats. Figure 2 illustrates typical qualitative differences between the two groups of animals. Responses to a 20 pps pulse train varied in ITD are shown for one IC neuron from an acutely deafened cat (top) and one from a congenitally deaf cat (bottom). In the neuron from an acutely deafened cat, the spikes are precisely locked to each stimulus pulse (Fig. $2 A$ ), and the firing rate is strongly modulated by ITD (Fig. $2 B$ ), as indicated by the large, highly significant value of the ITD SNR $(0.69, p<$ $0.001)$. The ITD tuning curve is peak shaped with a best ITD of $200 \mu$ s and shows a preference for contralateral-leading stimuli. This neuron has no spontaneous activity, as is the case for most IC neurons in acutely deafened cats.

In contrast, in the neuron from a congenitally deaf cat, there is significant spontaneous activity (4.1 spikes/s), as commonly observed in this group of animals. During stimulation by the $20 \mathrm{pps}$ pulse train, each pulse suppresses the spontaneous activity for $>50 \mathrm{~ms}$, followed by a poorly timed rebound of activity before the next pulse (Fig. 2C). The end of the pulse train is also followed by a period of rebound activity exceeding the spontaneous rate and lasting $>100 \mathrm{~ms}$. The mean firing rate is not obviously modulated by ITD (Fig. 2D), consistent with the small, statistically insignificant value of $\operatorname{ITD} \operatorname{SNR}(0.15, p=0.95)$.

Figure $3 A$ shows the distributions of ITD SNR for the two groups of animals. In acutely deafened cats, ITD SNR is distributed almost uniformly across the entire range from 0 (poor ITD coding) to almost 1 (highly reliable ITD coding). In contrast, in congenitally deaf cats, there are many more neurons with low ITD SNRs and fewer with high ITD SNRs. The median ITD SNR is significantly lower in the congenitally deaf group ( 0.19 vs 0.45 , $p<0.001$, Wilcoxon's rank-sum test). We classified as "ITD-
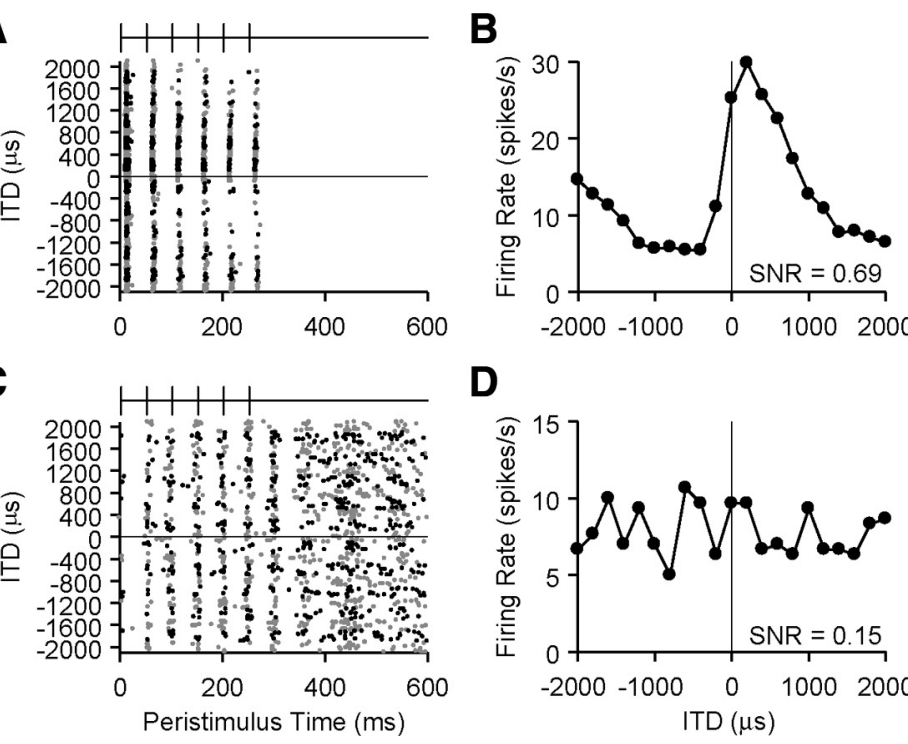

D

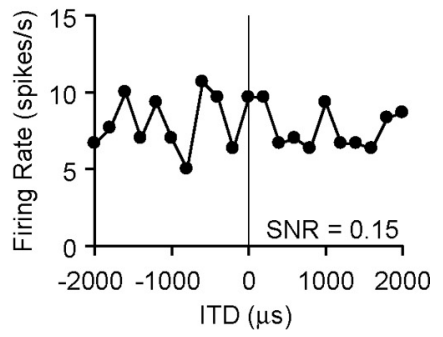

Figure 2. ITD tuning of two example neurons illustrating typical differences between acutely deafened (top row) and congenitally deaf (bottom row) cats. A, C, Temporal discharge patterns (dot rasters) as a function of ITD. Alternating colors indicate blocks of stimulus trials at different ITDs. Stimulus pulse train (20 pps) shown at the top. B, D, Firing rate versus ITD.
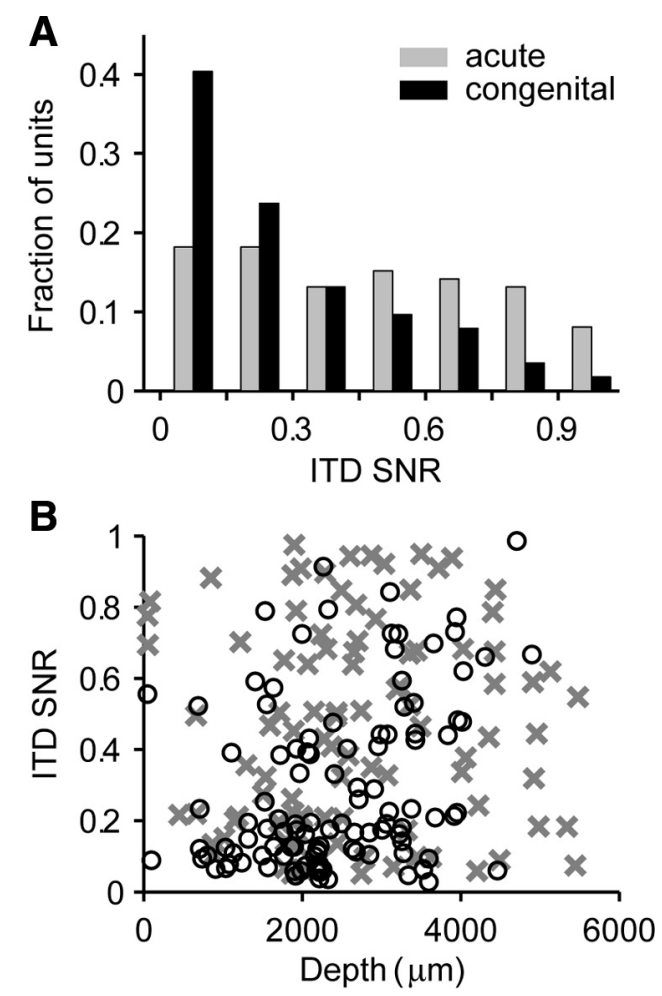

Figure 3. ITD-sensitive neurons are less prevalent in congenitally deaf cats. $A$, Distributions of ITD SNR for the samples of IC neurons in the two groups of animals. $B$, Scatter plot of ITD SNR versus recording depth from dorsal surface of IC. Crosses, Acutely deafened cats; circles, congenitally deaf cats.

sensitive" neurons for which the ITD SNR is significantly greater than 0 at the $p=0.025$ level. Only 48\% (55 of 114) of neurons in congenitally deaf cats were ITD sensitive by this criterion compared with $84 \%$ ( 83 of 99) in acutely deafened cats (Table 2). Thus, approximately half as many IC neurons are ITD sensitive in congenitally deaf cats compared with acutely deafened cats.

The fraction of ITD-sensitive neurons in our samples from both groups of animals might be influenced by biases in the dis- 
Table 2. Summary of single-unit response properties in bilaterally implanted cats

\begin{tabular}{lclllll}
\hline Animal group & $n$ & ITD sensitive & Median ITD SNR & Median spontaneous rate (spikes/s) & Median latency (ms) & Median jitter (ms) \\
\hline Acutely deafened & 99 & $84 \%$ & 0.45 & 0.0 & 7.02 & 0.41 \\
Congenitally deaf & 114 & $48 \%$ & 0.19 & 3.0 & 6.51 & 0.53 \\
\hline
\end{tabular}
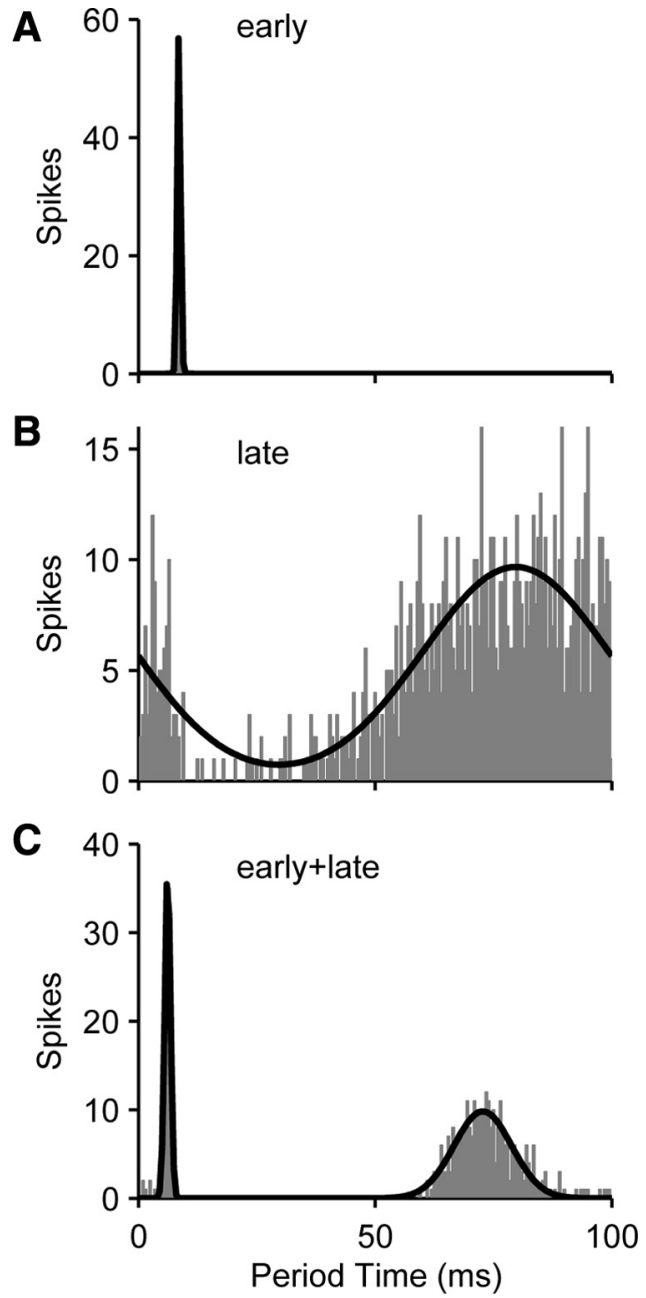

Figure 4. Examples of three types of temporal discharge patterns evoked by pulse-train stimulation in deaf animals. Period histograms plot spike times relative to the onset of each stimulus pulse with $0.5 \mathrm{~ms}$ resolution. $\boldsymbol{A}$, Precisely timed early response. $\boldsymbol{B}$, Poorly timed late responses presumably reflect suppression of spontaneous activity. C, Combination of early and late responses. Black lines, Automatic classification of period histogram shape based on sumof-Gaussians fit.

tributions of neurons along the cochleotopic axis of the IC. For example, because the intracochlear electrode array is inserted only a short distance into the cochlea past the round window, it may be hard to find responsive neurons in low-frequency, dorsal regions of the $\mathrm{IC}$, which receive predominant inputs from the cochlear apex. This dorsal region is the primary target of projections from the medial superior olive (MSO) and thus might contain a higher proportion of ITD sensitive neurons. However, Figure $3 B$ shows that ITD SNR does not depend on the depth of the microelectrode recording site relative to the dorsal surface of the IC, in either group of animals. Furthermore, there are no major differences in the distribution of recording depths between the two groups of animals. Hence, the observed difference in prevalence of ITD sensitivity between the two groups of animals is not likely to reflect differences in the IC regions sampled.
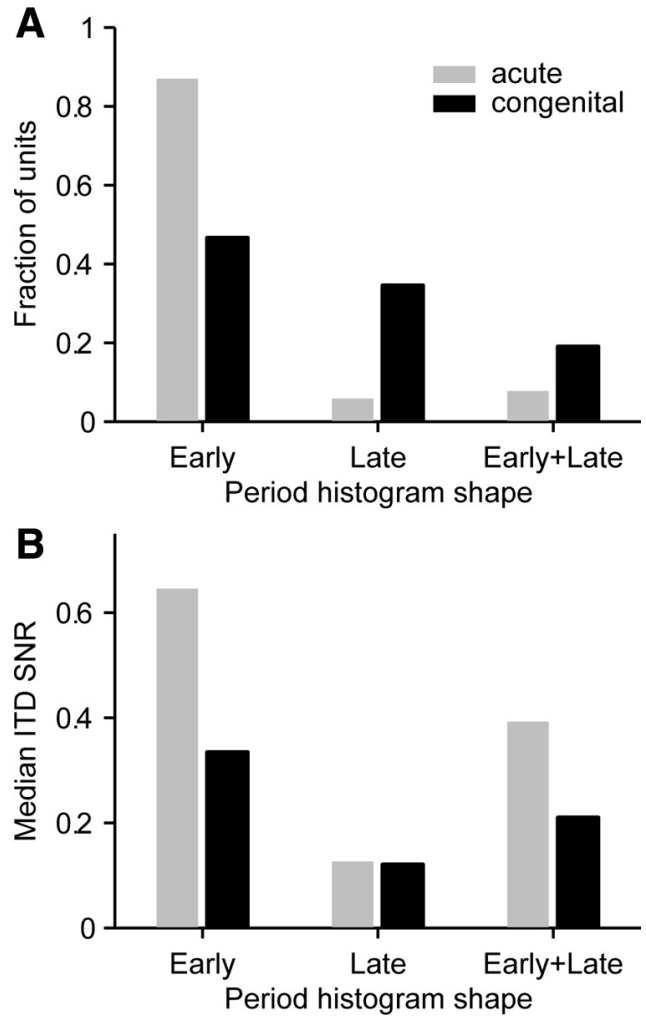

Figure 5. Late responses are more prevalent in congenitally deaf cats and are associated with poor ITD sensitivity. $\boldsymbol{A}$, Distributions of period histogram shapes compared between acutely deafened and congenitally deaf cats. $\boldsymbol{B}$, Comparison of median ITD SNR between groups of cats and across shape categories.

Relationship between ITD sensitivity and other response properties Neurons from the two groups of animals differ in other response properties besides ITD sensitivity, including temporal discharge patterns and spontaneous rate (Table 2). Because this is, to our knowledge, the first report of single-unit responses from the IC of congenitally deaf cats, we describe these differences in this section and also examine whether variations in these response properties correlate with degraded ITD sensitivity.

Three types of temporal discharge patterns to low-rate pulse trains were observed in the IC of both groups of animals (Fig. 4). Most commonly, each stimulus pulse evoked a short-latency, well-timed "early" response comprising one or two spikes (Fig. $4 A$ ). In other neurons, each stimulus pulse produced a shortlatency period of inactivity, followed by a long-latency, poorly timed "late" response (Fig. $4 \mathrm{~B}$ ). Late responses were frequently preceded by suppression of spontaneous activity, as in the neuron from a congenitally deaf cat in Figure 2. Although late responses could occur in the absence of spontaneous firing (so that suppression was not directly observable), they likely represent recovery from suppression or rebound from inhibition rather than direct excitatory effects. Early and late responses sometimes occurred together (Fig. 4C).

The vast majority of neurons in acutely deafened cats showed tightly pulse-locked early responses, whereas neurons from con- 
genitally deaf cats showed a mixture of excitatory and suppressive effects (Fig. 5A). Almost every neuron in acutely deafened cat had an early component in its response (either alone or in combination with a late response) compared with only two-thirds of the neurons in congenitally deaf cat (94 vs $66 \%$ ). Conversely, late responses rarely occurred in acutely deafened cats but were present half the time in congenitally deaf cats ( 13 vs $53 \%)$. The difference in the incidence of response shapes between the groups of cats was highly significant $(p<$ $0.001, \chi^{2}$ test). The increased incidence of poorly timed late responses in congenitally deaf cats is consistent with the lower ABR wave 4 amplitude in this group of animals, although wave 4 represents the synchronized activity of ascending inputs to the IC rather than IC activity itself (Melcher and Kiang, 1996).

The presence of a late response in the discharge pattern was typically associated with degraded ITD sensitivity (Fig. 5B). Across both groups of cats, the median ITD SNR was 0.13 in units with only a late response versus 0.57 in units with only an early response. Thus, the lower prevalence of well-timed, pulse-evoked spikes clearly contributes to degraded ITD sensitivity in the congenitally deaf cat. However, even among early responding units, the median ITD SNR was still twice as large in acutely deafened cats as in congenitally deaf cats ( 0.64 vs 0.33$)$.

A possible explanation for the difference in ITD sensitivity among early responding neurons could be differences in spike timing. We quantified mean spike latency and latency jitter for each unit using the mean and SD of Gaussian curves fitted to the early responses. Spike latency distributions across our samples of IC neurons were similar between acutely deafened and congenitally deaf cats (Fig. 6A). The median spike latency was slightly shorter in congenitally deaf cat, consistent with the small differences in ABR wave 4 latencies (Fig. $1 F$ ), but the difference was not significant (6.51 vs $7.03 \mathrm{~ms}, p=0.11$, Wilcoxon's rank-sum test). Shepherd et al. (1999) found a similar median latency in the IC of acutely deafened cats $(7.02 \mathrm{~ms})$ but a slightly larger median latency $(7.35 \mathrm{~ms})$ in cats that were neonatally deafened by ototoxic drugs. It is difficult to say whether this is a genuine difference between the two models of early-onset deafness or a result of subtle differences in methods (Shepherd et al. compare latencies at stimulus levels that produce the same probability of discharge, whereas we choose levels that maximize the ITD SNR). In any event, ITD sensitivity does not appear to be related to mean spike latency among early responding units (Fig. 6D).

Figure $6 B$ compares distributions of spike latency jitter (a measure of the precision of spike timing) between the two groups of deaf cats. The median jitter was slightly larger in congenitally deaf cats ( 0.53 vs $0.41 \mathrm{~ms})$, but the difference was not significant $(p=0.80$, Wilcoxon's rank-sum test). Shepherd et al. (1999) observed larger spike jitter in neonatally deafened animals compared with acutely deafened animals. There is a small tendency for units with large jitter to have small ITD SNR (Fig. $6 E$ ), but the converse is not true: units with very precise spike timing can still have very poor ITD sensitivity.

Spontaneous activity, typically measured over a 20 s period of silence, was more prevalent in congenitally deaf cats, in which $51 \%$ of the units had spontaneous rates $>2.5$ spikes/s compared
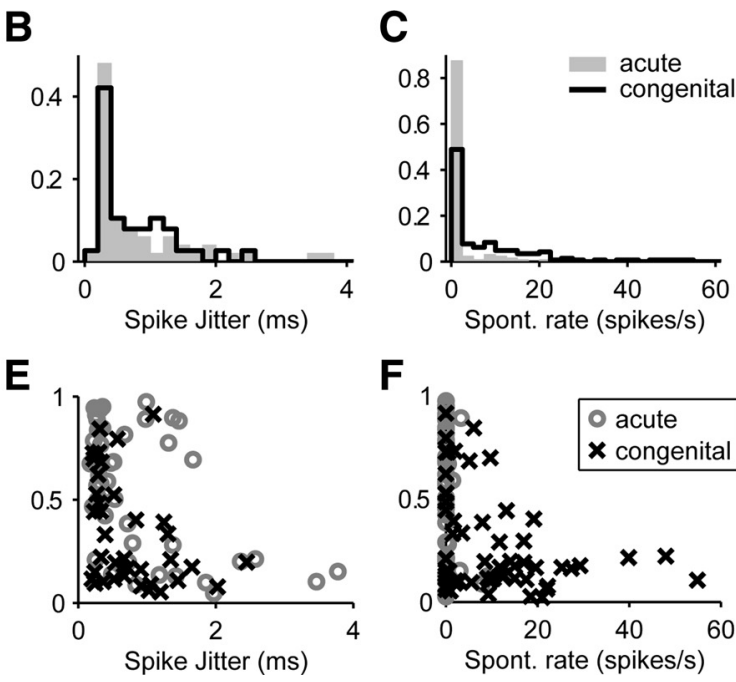

Figure 6. Effect of congenital deafness on spontaneous rate and spike timing. $\boldsymbol{A}-\boldsymbol{C}$, Histograms comparing the distributions of 作

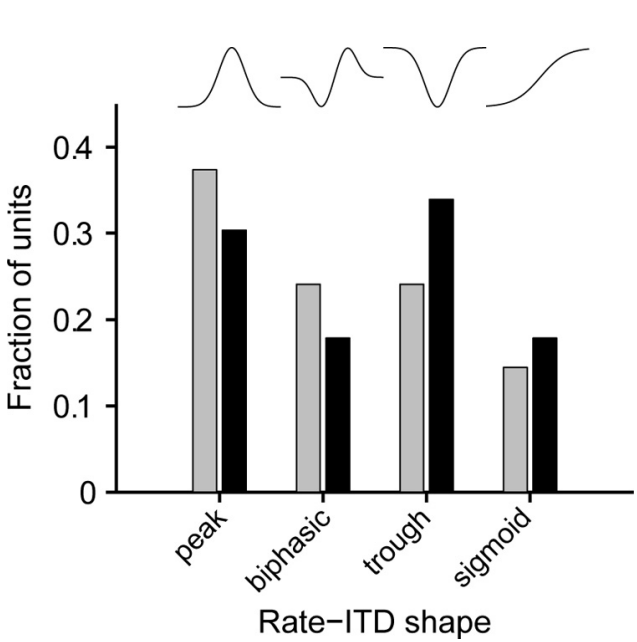

Figure 7. Shapes of rate-ITD curves do not differ between acutely deafened and congenitally deaf cats. Histograms show incidence of rate-ITD curve shapes based on the four templates (top) of Smith and Delgutte (2007). Analysis limited to IC neurons with statistically significant ITD SNRs.

with $13 \%$ in acutely deafened cats (Fig. 6C). The difference in median spontaneous rates between the two groups ( 0.0 vs 3.0 spikes/s) was highly significant ( $p<0.001$, Wilcoxon's rank-sum test). Spontaneous activity was almost always suppressed by stimulation, consistent with the observations of Shepherd et al. (1999) who also observed a higher prevalence of spontaneous activity in neonatally deafened cats. Figure $6 F$ shows that low spontaneous rate units tend to have low ITD SNR, but the converse is not true, i.e., poor ITD coding can occur even when there is no spontaneous activity.

In summary, IC neurons from congenitally deaf cats show increased spontaneous activity, a higher prevalence of late responses, slightly decreased response latencies, and increased latency jitter compared with neurons from acutely deafened cats. These changes go in the same direction as those observed by Shepherd et al. (1999) in neonatally deafened cats, with the exception of the change in spike latency (which is small in both studies and not even statistically significant in ours). Although some of these abnormalities in temporal response patterns cor- 
A
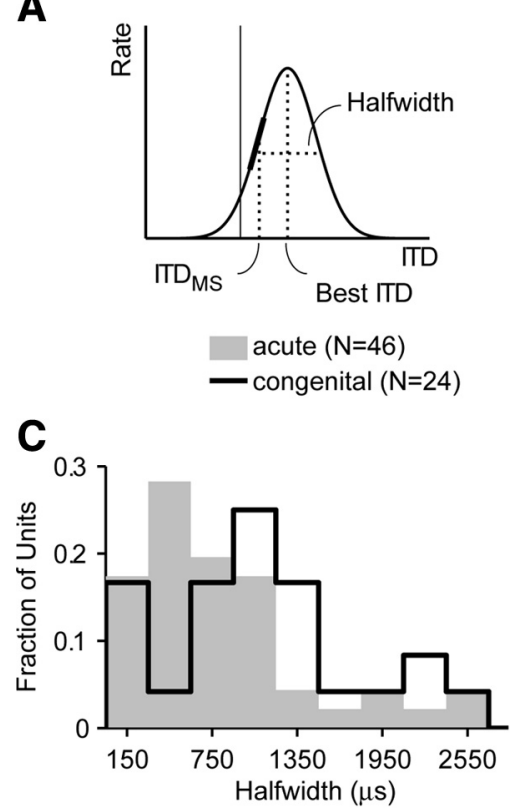

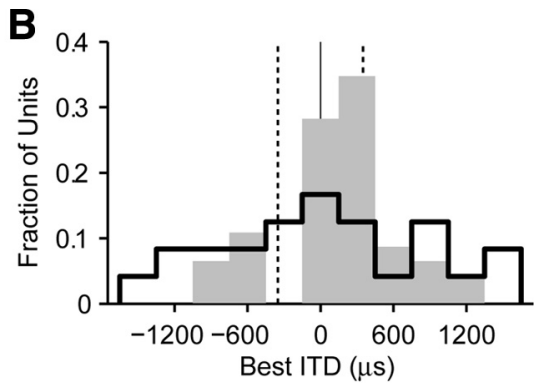

D

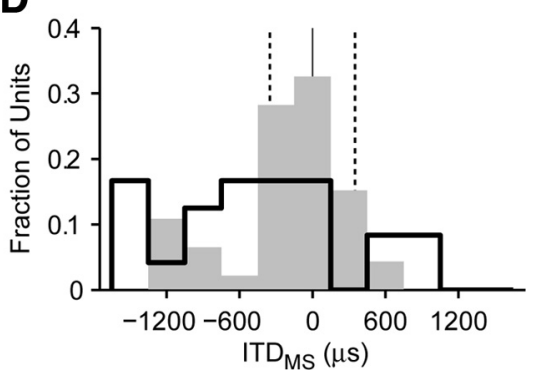

Figure 8. Congenital deafness alters ITD tuning metrics. Analysis applied to rate-ITD curves containing a peak. $\boldsymbol{A}$, Illustration of metrics derived from Gaussian fits to rate-ITD curves. Best ITD, ITD of the peak response; Halfwidth, width of rate-ITD curve at 50\% of maximum rate. ITD ${ }_{\mathrm{ms}}$ ITD for which the slope of rate-ITD curve is maximal. $\boldsymbol{B}$, Best ITD distribution is broader and lacks contralateral bias in congenitally deaf cats. $C$, Rate-ITD curves are broader in congenitally deaf cats. $\boldsymbol{D}, \mathrm{ITD}_{\mathrm{MS}}$ distribution is not concentrated in naturally occurring range of ITD in congenitally deaf cats. $\boldsymbol{B}, \boldsymbol{D}$, Dashed lines, approximate naturally occurring ITD range in cat.

relate somewhat with poor ITD sensitivity, they cannot wholly account for the decreased prevalence of ITD sensitive neurons in congenitally deaf cats. This is consistent with the idea that ITD sensitivity is first created peripheral from the IC, in the lateral and medial superior olives, so that precise spike timing is not a requirement for an ITD-sensitive unit in IC.

\section{ITD tuning curves}

We investigated whether there are differences in ITD tuning curves between the two groups of implanted cats for those neurons that were ITD sensitive based on the SNR metric. When multiple rate-ITD curves were measured (e.g., using different pulse rates, stimulus levels, etc.), we used the rate-ITD curve yielding the maximum ITD SNR.

Figure 7 compares the distributions of shapes of ITD tuning curves between the two groups of animals. There were slightly more peak and biphasic shapes in acutely deafened cats and more troughs and sigmoids in congenitally deaf cats, but the difference in distributions was not statistically significant $\left(p=0.48, \chi^{2}\right.$ test).

In acutely deafened cats, the distribution of best ITD (Fig. 8 B) has a clear contralateral bias (mean of $136 \mu \mathrm{s}$ ) and is relatively concentrated around the mean (SD of $518 \mu \mathrm{s}$ ). In congenitally deaf cats, the distribution is centered closer to the midline (mean of $23 \mu \mathrm{s}$ ) and is significantly broader (SD of $839 \mu \mathrm{s}, p<0.001$, Levene's test). In acutely deafened cats, the distribution of halfwidths of ITD tuning (Fig. 8C) is relatively narrow (median of $685 \mu \mathrm{s}$ ), whereas in congenitally deaf cats, it is broader with a large median $(1022 \mu \mathrm{s})$. The difference in medians just misses statistical significance ( $p=0.076$, Wilcoxon's rank-sum test). Finally, Figure $8 D$ shows the distributions of the ITD $_{\mathrm{MS}}$ at which the firing rate is most sensitive to changes in ITD. In the acutely deafened group, $67 \%$ of $\mathrm{ITD}_{\mathrm{MS}}$ fall within the range of naturally occurring ITDs for the cat (approximately $\pm 350 \mu \mathrm{s}$ ). In congen- itally deaf cats, the distribution is broader with a stronger ipsilateral bias, consistent with the larger half-widths and more variable best ITDs in that group, and only $33 \%$ of $\mathrm{ITD}_{\mathrm{MS}}$ lie within the natural range of ITDs. Thus, although some neurons in congenitally deaf cats show a rudimentary form of ITD sensitivity, ITD tuning properties for the population as a whole clearly differ from those in animals with normal auditory experience, with many neurons showing broad tuning poorly adapted for coding the ITDs encountered in the acoustic environment.

\section{Best ITD depends on sharpness of tuning} in acutely deafened cats

For broadband noise stimuli in normalhearing cats and guinea pigs, the best ITDs of low-frequency IC neurons tend to be inversely correlated to their best frequency (BF) (McAlpine et al., 2001; Hancock and Delgutte, 2004; Joris et al., 2006). This relationship is illustrated in Figure $9 A$ using IC data from normal-hearing cats pooled from several studies in our laboratory (Hancock and Delgutte, 2004; Devore et al., 2009). Figure $9 B$ shows that the best ITD is also positively correlated with half-width of ITD tuning (i.e., broadly tuned neurons tend to have large best ITDs). The trends in Figure 9, $A$ and $B$, are closely related because the main lobe of the rate-ITD curve for broadband stimuli widens with decreasing BF (Yin et al., 1986; McAlpine et al., 2001). This widening is apparent in the average rate-ITD curves for each BF quintile (Fig. 9D). The correlation between best ITD and half-width tends to align the rising slopes of the rate-ITD curves near 0 ITD and misalign them at more lateral ITDs. This alignment is key in accounting for the greater psychophysical ITD acuity near the midline (Hancock and Delgutte, 2004).

It is, a priori, unclear whether the relationship between best ITD and half-width holds in the case of bilateral CI. In normalhearing animals, the dependence of half-width on BF for broadband stimuli primarily reflects the effects of cochlear filtering (Yin et al., 1986). Furthermore, there is evidence that small interaural mismatches in the BFs of the inputs to the binaural coincidence detector neurons likely contribute to the dependence of best ITD on BF (Joris et al., 2006; Day and Semple, 2009). With cochlear implants, however, one might not expect to observe these relationships because cochlear mechanisms for frequency selectivity are bypassed.

Nevertheless, Figure 9C shows that a positive correlation between best ITD and half-width does exist in the IC of acutely deafened, bilaterally implanted cats $\left(r^{2}=0.41, p<0.001\right)$. For this purpose, we combined our sample $(n=31)$ of peak-shaped and biphasic rate-ITD curves with a larger sample $(n=77)$ from Smith and Delgutte (2007a). A similar analysis could not be conducted in congenitally deaf cats because our sample of ITD-sensitive neurons was too small to characterize the joint distribution of ITD tuning parameters. Figure $9 E$ shows the average rate-ITD curves for each quintile of half-width, illustrating alignment of slopes near the midline despite the wide variation in half-widths. Conversely, ITD $_{\mathrm{MS}}$ is uncorrelated with half-width, as shown in Figure $9 G\left(r^{2}=0.0013, p=0.70\right)$. These relation- 
ships are used in the following section to constrain a neural population model of perceptual ITD discrimination.

Psychophysics and neural population model of ITD discrimination

An important question is the extent to which the changes in neural ITD coding observed in congenital deafness affect ITD perception. The answer depends on assumptions about the central processing of the ITD information available in the activity pattern of the population of IC neurons. For example, good ITD discrimination might still be achievable with a small number of ITD-sensitive neurons if performance is primarily determined by the most sharply tuned neurons in the population. To approach these questions systematically and make our assumptions explicit, we used a signal detection model for assessing the impact of congenital deafness on ITD discrimination. For this purpose, we adapted to the deaf case a neural population model that was shown previously to account for key aspects of ITD discrimination in normal-hearing listeners (Hancock and Delgutte, 2004).

The normal-hearing model is a twodimensional grid of neurons (Fig. 10A), each of which is characterized by a rateITD curve whose shape is determined by two independently distributed parameters: BF and best interaural phase difference (best ITD $\times \mathrm{BF})$. The model predicts the sharper psychophysical ITD acuity on the midline compared with more lateral locations (Mossop and Culling, 1998) by summing the rate-ITD curves of model neurons across BF. This summation harnesses the alignment of the rising slopes of the rate-ITD curves across BF near the midline (and their misalignment at lateral locations) to produce composite rateITD curves that are much steeper near the midline than at lateral locations.

Although BF is undefined in deaf animals, the tight correlation between best ITD and half-width of ITD tuning that is observed in both normal-hearing (Fig. 9B) and acutely deafened (Fig. 9C) cats makes it possible to use half-width as a proxy for BF in the deaf model. However, the normal-hearing model is based on the responses of neurons with $\mathrm{BF}<2 \mathrm{kHz}$, whereas the cochlear implant model is based on data spanning the entire cochleotopic axis (Fig. 3B). Thus, an important assumption is that the principle of operation of the model generalizes across $\mathrm{BF}$.

We constructed a population model for the bilateral CI case in which half-width and ITD $_{\mathrm{MS}}$ vary along the two independent axes of the grid of model neurons (Fig. 10A) because these parameters are uncorrelated in the physiological data (Fig. 9G). We started with a model for acutely deafened cats using the constraints imposed by the physiological data from this group of animals and then modified this model for the congenitally deaf case. In the acutely deafened case, all model neurons are ITD sensitive, and half-width and ITD $_{\mathrm{MS}}$ are independently distributed according to the data of Figure 9G. In every other respect, the bilateral CI model operates in identical manner to the normal-hearing model (see Materials and Methods). Importantly, the sole free parameter of the model, the detection efficiency $\varepsilon$ (Eq. 3), was chosen to produce accurate predictions of normal-hearing ITD discrimination for broadband noise (Hancock and Delgutte, 2004), making the model completely constrained in the CI case.

To obtain psychophysical data to directly test model predictions, we measured ITD discrimination for 50 pps pulse trains in two postlingually deaf human bilateral cochlear implant users (Table 1). The gray line in Figure $10 \mathrm{~B}$ shows the mean ITD JNDs as a function of reference ITD for these two listeners. JNDs are small near the midline ( $90 \mu \mathrm{s})$ but increase as the reference ITD increases, similar to the trend exhibited by normal-hearing listeners (Mossop and Culling, 1998). The acutely deafened model 


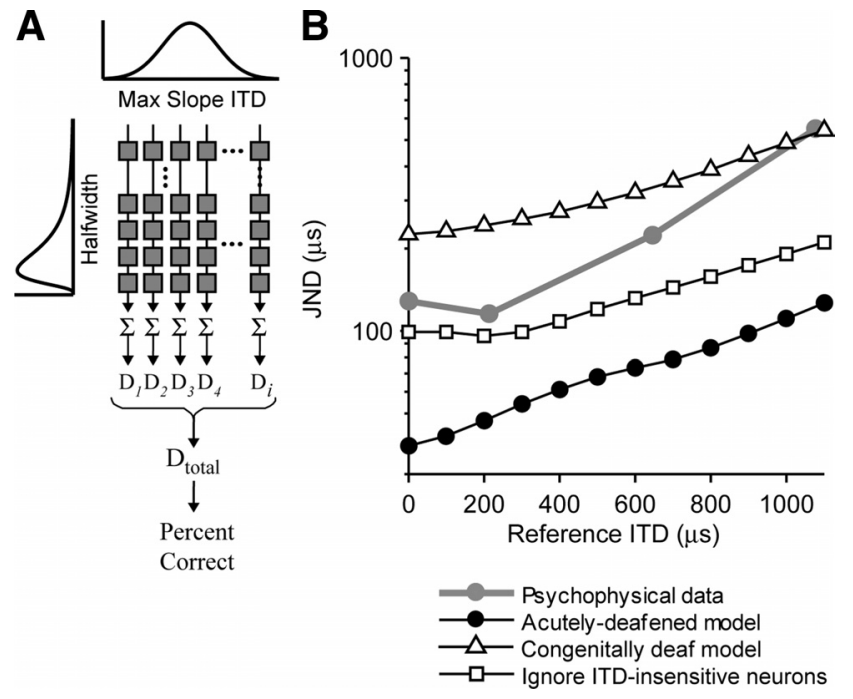

Figure 10. Physiologically based model of psychophysical ITD discrimination with bilateral Cl. $A$, Grid of model neurons. Each model neuron has a Gaussian-shaped rate-ITD curve. Half-width varies in one dimension, $\mathrm{TD}_{\mathrm{MS}}$ in the other. Rates are summed across half-widths before computing $D$ values, and then the $D$ values are combined optimally across ITD ${ }_{\text {MS }}$. $B$, ITD JND versus reference ITD for two bilateral implant subjects (gray line) and various model configurations.

(Fig. $10 B$, filled black circles) predicts a JND of $\sim 50 \mu$ s on the midline that increases for lateral reference ITDs. Although the trend in the model prediction approximately parallels the psychophysical data, the simulation clearly illustrates the discrepancy that motivated this study: the model based on neural ITD coding in acutely deafened cats predicts better ITD discrimination than is actually observed in bilateral CI users, even very good performers.

We hypothesize that the abnormal neural ITD coding observed in congenitally deaf cats may better predict the psychophysics because human implantees typically experience long periods of binaural deprivation. We explored this hypothesis by constructing a "congenitally deaf" model incorporating the observed neural abnormalities. Specifically, the decreased incidence of ITD-sensitive IC neurons was modeled by making half of the model neurons fire at a constant rate as a function of ITD. These insensitive neurons degrade model performance by adding noise to the decision variable. Furthermore, the alteration of neural ITD tuning properties for ITD-sensitive neurons was simulated by increasing the widths of the distributions of half width and ITD $_{\mathrm{MS}}$ as shown in the data of Figure $8, B$ and $D$. Imposing the congenital deafness constraints increases the predicted JNDs by nearly an order of magnitude relative to the acutely deafened model but preserves the general trend for JNDs to increase away from the midline (Fig. $10 \mathrm{~B}$, triangles).

The ITD discrimination performance predicted by the congenitally deaf model is approximately a factor of three worse than psychophysical performance. Possibly, these good-performing subjects (who received enough auditory experience to acquire fluent speech before becoming deaf) are intermediate with respect to auditory experience between the two extremes of acute and congenital deafness embodied by the two model versions. Alternatively, the central processor may learn to ignore the uninformative (i.e., ITD-insensitive) neurons within the IC neuron population to optimize performance. This condition was simulated by computing ITD JNDs using only the ITD-sensitive neurons in the congenitally deaf model (Fig. $10 \mathrm{~B}$, squares). In this configuration, the model produces a closer match to the average psychophysical performance across all reference ITDs, although the performance is still slightly overestimated and the dependence of JND on reference ITD is shallower than in the data.

The validity of the model is ultimately limited by its underlying assumptions, including the generality of the ITD discrimination mechanism to high-frequency pathways and the applicability of neurophysiology in anesthetized cat to human perception. However, to the extent that the model accurately describes ITD discrimination in normal hearing and the assumptions similarly limit its acutely deafened and congenitally deaf adaptations, the model provides a tentative quantitative assessment of the impact on perception resulting from the kinds of neural deficits we observed. In general, the modeling results support our hypothesis that abnormalities in neural ITD coding resulting from deprivation of auditory experience can have a substantial impact on perceptual ITD discrimination performance.

\section{Discussion}

ITD discrimination by human bilateral CI users is generally poor compared with normal-hearing listeners. In contrast, neural ITD coding by single units in the IC of acutely deafened, bilaterally implanted cats is essentially normal (Smith and Delgutte, 2007a). A confounding factor in comparing the human psychophysical data with the animal neurophysiology is the extent of previous binaural hearing experience. Although the cats were deafened within 1 week of experimentation, humans often experience months or years of deafness and/or monolateral stimulation before receiving a second cochlear implant. To begin addressing this issue, we compared neural ITD coding in two groups of animals that contrast maximally in binaural experience: acutely deafened and congenitally deaf cats. We find that congenital deafness has a major impact on ITD coding in the IC. Only approximately half as many neurons were ITD sensitive in the IC of congenitally deaf cats compared with acutely deafened cats. Moreover, the ITD tuning curves of neurons that did exhibit ITD sensitivity in congenitally deaf cats were broadly tuned, and the distribution of their tuning parameters was ill adapted for providing good discrimination within the naturally occurring range of ITD. The effects of auditory deprivation on predictions of ITD discrimination by a signal detection model tightly constrained by IC physiology in deaf animals were consistent with the perceptual deficits observed in bilateral CI users.

Overall, our results suggest that, although a rudimentary form of ITD sensitivity exists in the absence of auditory inputs, auditory experience is necessary for normal function of the brainstem neural circuits processing ITD. However, the congenitally deaf model does not allow us to distinguish effects of deafness on the normal maturation of the ITD-processing pathway during the neonatal period from degradation of the pathway resulting from extended periods of deafness after development. Additional studies with animals in which the onset and duration of deafness are systematically varied are needed to address this issue.

The deficits in ITD coding observed in IC single units are broadly similar to those reported previously in multiunits from the auditory cortex of deaf white cat (Tillein et al., 2010), including reduced incidence of ITD-sensitive units and weaker contralateral bias in best ITD distributions. However, differences in methods and analysis techniques make it difficult to tell whether the cortex simply inherits its deficits from the IC or whether additional deficits arise at the thalamocortical level.

Our finding of significant effects of auditory deprivation on ITD coding at the level of auditory brainstem contrasts with studies of plasticity in cochleotopic organization and binaural pro- 
cessing of ILD. In these studies, plasticity is either observed only at the thalamocortical level or is much more dramatic in the cortex than in the IC, whether the plasticity is induced by restricted cochlear lesions (Robertson and Irvine, 1989; Irvine and Rajan, 1994), monaural conductive hearing loss (Popescu and Polley, 2010), or neonatal deafening (Snyder et al., 1990; Raggio and Schreiner, 1999). Auditory experience may be particularly critical for maturation of the ITD-processing circuitry in auditory brainstem because the operation of this circuit places extraordinary requirements on the precision of spike timing. ITD processing may provide a particularly sensitive model system for studies of neural development, plasticity, and repair.

By what mechanisms might congenital deafness affect ITD coding in IC neurons? Because deprivation of auditory experience does not preclude precise spike timing to electric pulse trains in the auditory nerve (Shepherd and Javel, 1997; Sly et al., 2007), the deficits are likely to arise primarily in the brainstem. Congenitally deaf cats and mice show structural abnormalities in the end bulbs of Held, the specialized synapses between auditory nerve fibers and spherical bushy cells (SBCs) of the cochlear nucleus (Ryugo et al., 1997, 1998; Lee et al., 2003). Transmission at this critical synapse is altered in congenitally deaf mutant mice in vitro (Oleskevich and Walmsley, 2002). Disruption of this synapse specialized for precise transmission of timing information is likely to impair the encoding of ITD by neurons in the MSO and lateral superior olive (LSO), which receive excitatory inputs from SBCs.

Interruption of auditory inputs by cochlear ablation also results in abnormalities in the calyces of Held, the giant synapses formed by axons of cochlear nucleus globular bushy cells on medial nucleus of the trapezoid body (MNTB) cells (Jean-Baptiste and Morest, 1975). The inhibitory projections from MNTB are critical to ITD sensitivity of LSO neurons (Joris and Yin, 1995) and also play a role in ITD tuning in MSO (Brand et al., 2002). The normal maturation of inhibitory synapses in MSO depends on auditory experience because these synapses have less focused spatial distributions in both congenitally deaf cats (Tirko et al., 2009) and normal-hearing gerbils raised in omnidirectional noise (Kapfer et al., 2002). This reduction of inhibition to MSO neurons could contribute to the increase in spontaneous activity in IC units. In both MSO and ventral cochlear nucleus, normal synapses can be partially restored in congenitally deaf animals by chronic electric stimulation through cochlear implants (Ryugo et al., 2005; Tirko et al., 2009).

An imbalance between excitation and inhibition might also contribute to deficits in ITD sensitivity in congenitally deaf cats. Interruption of peripheral auditory inputs causes a downregulation of inhibitory gain in brainstem auditory nuclei, including cochlear nucleus, LSO, and IC (Takesian et al., 2009). A balance between ipsilateral excitation and contralateral inhibition is essential for ITD sensitivity in LSO neurons (Joris and Yin, 1995), and inhibition helps make ITD coding robust to variations in ILD and overall level (Peña et al., 1996; Dasika et al., 2005). Barbiturate anesthesia may also affect the balance between excitation and inhibition and contribute to the strength and prevalence of longlatency responses. However, it is unlikely to account for differences between acutely deafened and congenitally deaf cats because identical methods were used in both groups.

In normal-hearing cats, guinea pigs, and gerbils, firing rates of IC and MSO neurons are most sensitive to changes in ITD within the naturally occurring range of ITD as a result of a correlation between best ITD and the width of ITD tuning curves (McAlpine et al., 2001; Brand et al., 2002; Hancock and Delgutte, 2004). The cochlear traveling wave is likely to contribute to this correlation
(Joris et al., 2006), although central neural mechanisms including conduction delays and inhibition may also play a role. Interestingly, we found that the trend also holds in acutely deafened, bilaterally implanted cats (Fig. 9C), although cochlear mechanics are bypassed. The following scenario might account for this finding. Early in development, there might be a broad range of sharpness of ITD tuning and, independently, a broad distribution of best ITDs as observed in adult congenitally deaf cats (Fig. 8) and in animals raised in omnidirectional acoustic environments (Seidl and Grothe, 2005). Auditory experience might provide selective pressure to create a neural network maximally sensitive to changes in ITD about the midline by strengthening synaptic inputs that favor correlation between half-width and best ITD and pruning those that do not, regardless of whether the correlation for each particular input is produced by cochlear or central mechanisms.

Our finding of major deficits in ITD coding in congenitally deaf cats is in harmony with psychophysical and evoked potential studies showing that auditory experience (especially during the neonatal period) impacts ITD sensitivity in human bilateral CI users. The one order of magnitude difference in ITD JNDs predicted by our signal detection model between congenitally deaf animals and acutely deafened animals is in line with the differences in performance among subjects differing in the timing and duration of deafness in psychophysical studies (Poon et al., 2009; Litovsky et al., 2010). Litovsky et al. (2010) found that prelingually deaf subjects could not lateralize 100 pps pulse trains based on ITD, whereas subjects with childhood and adult onset deafness could. Importantly, all subjects could lateralize based on ILD, showing that the effect of deprivation of early auditory experience is specific to ITD processing. Gordon et al. (2008) measured ABRs in bilaterally implanted young children with early onset (probably congenital) deafness 9 months after the beginning of binaural implant use. They find delayed BIC latencies if the interval between the two implantations exceeds 2 years but not in cases of simultaneous or short-delay implantations, pointing to the importance of early binaural experience in the maturation of brainstem binaural circuits.

The present results raise important questions: does the period of auditory deprivation have to encompass the neonatal period to produce abnormalities in neural ITD coding, or do some of these abnormalities also occur in the case of adult-onset deafness? Can chronic stimulation through cochlear implants reverse these abnormalities and improve ITD coding in deaf animals? If so, what stimulation paradigms and training regimens are most effective for this purpose? Answers to such questions will shed additional light on the development and plasticity of neural ITD coding and likely suggest methods for improving the ability of bilateral CI listeners to use ITD information.

\section{References}

Brand A, Behrend O, Marquardt T, McAlpine D, Grothe B (2002) Precise inhibition is essential for microsecond interaural time difference coding. Nature 417:543-547.

Dasika VK, White JA, Carney LH, Colburn HS (2005) Effects of inhibitory feedback in a network model of avian brain stem. J Neurophysiol 94:400-414.

Day ML, Semple MN (2009) Cochlear disparity as a source of internal delay: evidence in the medial superior olive. Soc Neurosci Abstr 35:259.215.

Devore S, Ihlefeld A, Hancock K, Shinn-Cunningham B, Delgutte B (2009) Accurate sound localization in reverberant environments is mediated by robust encoding of spatial cues in the auditory midbrain. Neuron 62:123-134.

Dobie RA, Norton SJ (1980) Binaural interaction in human auditory evoked potentials. Electroencephalogr Clin Neurophysiol 49:303-313. 
Gordon KA, Valero J, Papsin BC (2007) Binaural processing in children using bilateral cochlear implants. Neuroreport 18:613-617.

Gordon KA, Valero J, van Hoesel R, Papsin BC (2008) Abnormal timing delays in auditory brainstem responses evoked by bilateral cochlear implant use in children. Otol Neurotol 29:193-198.

Grantham DW, Ashmead DH, Ricketts TA, Haynes DS, Labadie RF (2008) Interaural time and level difference thresholds for acoustically presented signals in post-lingually deafened adults fitted with bilateral cochlear implants using CIS + processing. Ear Hear 29:33-44.

Green DM, Swets JA (1988) Signal detection theory and psychophysics. Los Altos, CA: Peninsula.

Hancock KE, Delgutte B (2004) A physiologically based model of interaural time difference discrimination. J Neurosci 24:7110-7117.

Hartmann WM, Rakerd B (1989) On the minimum audible angle: a decision theory approach. J Acoust Soc Am 85:2031-2041.

Heid S, Hartmann R, Klinke R (1998) A model for prelingual deafness, the congenitally deaf white cat: population statistics and degenerative changes. Hear Res 115:101-112.

Irvine DRF, Rajan R (1994) Plasticity of frequency organization in inferior colliculus of adult cats with unilateral restricted cochlear lesions. Assoc Res Otolaryngol Abstr 17:82.

Jean-Baptiste M, Morest DK (1975) Transneuronal changes of synaptic endings and nuclear chromatin in the trapezoid body following cochlear ablations in cats. J Comp Neurol 162:111-134.

Joris PX, Yin TC (1995) Envelope coding in the lateral superior olive. I. Sensitivity to interaural time differences. J Neurophysiol 73:1043-1062.

Joris PX, Van de Sande B, Louage DH, van der Heijden M (2006) Binaural and cochlear disparities. Proc Natl Acad Sci U S A 103:12917-12922.

Kapfer C, Seidl AH, Schweizer H, Grothe B (2002) Experience-dependent refinement of inhibitory inputs to auditory coincidence-detector neurons. Nat Neurosci 5:247-253.

Laback B, Pok SM, Baumgartner WD, Deutsch WA, Schmid K (2004) Sensitivity to interaural level and envelope time differences of two bilateral cochlear implant listeners using clinical sound processors. Ear Hear 25:488-500.

Laback B, Majdak P, Baumgartner WD (2007) Lateralization discrimination of interaural time delays in four-pulse sequences in electric and acoustic hearing. J Acoust Soc Am 121:2182-2191.

Lawson DT, Wilson BS, Zerbi M, van den Honert C, Finley CC, Farmer JC Jr, McElveen JT Jr, Roush PA (1998) Bilateral cochlear implants controlled by a single speech processor. Am J Otol 19:758-761.

Lee DJ, Cahill HB, Ryugo DK (2003) Effects of congenital deafness in the cochlear nuclei of Shaker-2 mice: an ultrastructural analysis of synapse morphology in the endbulbs of Held. J Neurocytol 32:229-243.

Levine RA (1981) Binaural interaction in brainstem potentials of human subjects. Ann Neurol 9:384-393.

Levitt H (1971) Transformed up-down methods in psychoacoustics. J Acoust Soc Am [Suppl 2]49:467+.

Litovsky R, Parkinson A, Arcaroli J, Sammeth C (2006) Simultaneous bilateral cochlear implantation in adults: a multicenter clinical study. Ear Hear 27:714-731.

Litovsky RY, Jones GL, Agrawal S, van Hoesel R (2010) Effect of age at onset of deafness on binaural sensitivity in electric hearing in humans. J Acoust Soc Am 127:400-414.

Litvak LM, Smith ZM, Delgutte B, Eddington DK (2003) Desynchronization of electrically evoked auditory-nerve activity by high-frequency pulse trains of long duration. J Acoust Soc Am 114:2066-2078.

McAlpine D, Jiang D, Palmer AR (2001) A neural code for low-frequency sound localization in mammals. Nat Neurosci 4:396-401.

Melcher JR, Kiang NY (1996) Generators of the brainstem auditory evoked potential in cat. III. Identified cell populations. Hear Res 93:52-71.

Mossop JE, Culling JF (1998) Lateralization of large interaural delays. J Acoust Soc Am 104:1574-1579.

Oleskevich S, Walmsley B (2002) Synaptic transmission in the auditory brainstem of normal and congenitally deaf mice. J Physiol 540:447-455.

Peña JL, Viete S, Albeck Y, Konishi M (1996) Tolerance to sound intensity of binaural coincidence detection in the nucleus laminaris of the owl. J Neurosci 16:7046-7054.

Poon BB, Eddington DK, Noel V, Colburn HS (2009) Sensitivity to interaural time difference with bilateral cochlear implants: development over time and effect of interaural electrode spacing. J Acoust Soc Am $126: 806-815$
Popescu MV, Polley DB (2010) Monaural deprivation disrupts development of binaural selectivity in auditory midbrain and cortex. Neuron 65:718-731.

Raggio MW, Schreiner CE (1999) Neuronal responses in cat primary auditory cortex to electrical cochlear stimulation. III. Activation patterns in short- and long-term deafness. J Neurophysiol 82:3506-3526.

Robertson D, Irvine DR (1989) Plasticity of frequency organization in auditory cortex of guinea pigs with partial unilateral deafness. J Comp Neurol 282:456-471.

Ryugo DK, Pongstaporn T, Huchton DM, Niparko JK (1997) Ultrastructural analysis of primary endings in deaf white cats: morphologic alterations in endbulbs of Held. J Comp Neurol 385:230-244.

Ryugo DK, Rosenbaum BT, Kim PJ, Niparko JK, Saada AA (1998) Single unit recordings in the auditory nerve of congenitally deaf white cats: morphological correlates in the cochlea and cochlear nucleus. J Comp Neurol 397:532-548.

Ryugo DK, Cahill HB, Rose LS, Rosenbaum BT, Schroeder ME, Wright AL (2003) Separate forms of pathology in the cochlea of congenitally deaf white cats. Hear Res 181:73-84.

Ryugo DK, Kretzmer EA, Niparko JK (2005) Restoration of auditory nerve synapses in cats by cochlear implants. Science 310:1490-1492.

Seeber BU, Fastl H (2008) Localization cues with bilateral cochlear implants. J Acoust Soc Am 123:1030-1042.

Seidl AH, Grothe B (2005) Development of sound localization mechanisms in the Mongolian gerbil is shaped by early acoustic experience. J Neurophysiol 94:1028-1036.

Shepherd RK, Javel E (1997) Electrical stimulation of the auditory nerve. I. Correlation of physiological responses with cochlear status. Hear Res 108:112-144.

Shepherd RK, Baxi JH, Hardie NA (1999) Response of inferior colliculus neurons to electrical stimulation of the auditory nerve in neonatally deafened cats. J Neurophysiol 82:1363-1380.

Sly DJ, Heffer LF, White MW, Shepherd RK, Birch MG, Minter RL, Nelson NE, Wise AK, O'Leary SJ (2007) Deafness alters auditory nerve fibre responses to cochlear implant stimulation. Eur J Neurosci 26:510-522.

Smith ZM, Delgutte B (2007a) Sensitivity to interaural time differences in the inferior colliculus with bilateral cochlear implants. J Neurosci 27:6740-6750.

Smith ZM, Delgutte B (2007b) Using evoked potentials to match interaural electrode pairs with bilateral cochlear implants. J Assoc Res Otolaryngol 8:134-151.

Snyder RL, Rebscher SJ, Cao KL, Leake PA, Kelly K (1990) Chronic intracochlear electrical stimulation in the neonatally deafened cat. I. Expansion of central representation. Hear Res 50:7-33.

Takesian AE, Kotak VC, Sanes DH (2009) Developmental hearing loss disrupts synaptic inhibition: implications for auditory processing. Future Neurol 4:331-349.

Tillein J, Hubka P, Syed E, Hartmann R, Engel AK, Kral A (2010) Cortica representation of interaural time difference in congenital deafness. Cereb Cortex 20:492-506.

Tirko N, Pongstaporn T, Ryugo DK (2009) Synaptic organization of MSO principal neurons in hearing, deaf, and cochlear-implanted cats. Assoc Res Otolaryngol Abstr 32:707.

van Hoesel RJ (2004) Exploring the benefits of bilateral cochlear implants Audiol Neurootol 9:234-246.

van Hoesel RJ (2007) Sensitivity to binaural timing in bilateral cochlear implant users. J Acoust Soc Am 121:2192-2206.

van Hoesel RJ, Tyler RS (2003) Speech perception, localization, and lateralization with bilateral cochlear implants. J Acoust Soc Am 113:1617-1630.

West CD, Harrison JM (1973) Transneuronal cell atrophy in the congenitally deaf white cat. J Comp Neurol 151:377-398.

Xu SA, Shepherd RK, Chen Y, Clark GM (1993) Profound hearing loss in the cat following the single co-administration of kanamycin and ethacrynic acid. Hear Res 70:205-215.

Yin TC, Chan JC, Irvine DR (1986) Effects of interaural time delays of noise stimuli on low-frequency cells in the cat's inferior colliculus. I. Responses to wideband noise. J Neurophysiol 55:280-300.

Zurek PM (1992) Binaural advantages and directional effects in speech intelligibility. In: Acoustical factors affecting hearing aid performance (Studebaker GA, Hochberg I, eds). Boston: Allyn and Bacon. 